\title{
An anti - obesity drug: Caralluma fimbriata wall.
}

\author{
Review Article
}

\author{
Sharma Ravindra ${ }^{*}$, Agrawal Rachna ${ }^{2}$, Malviya Reeta ${ }^{3}$, Rama Murthy $\mathbf{A}^{4}$ \\ 1. P.G. Scholar, Dept. of P.G. Studies in Dravya Guna, \\ 2. P.G. Scholar, Dept. of P.G. Studies in Swasthvrit, \\ 3. P.G. Scholar, Dept. of P.G. Studies in Dravya Guna, \\ 4. Asst.Prof. Dept. of P.G. Studies in Dravya Guna, \\ National Institute of Ayurveda, Jaipur, Rajasthan.
} \begin{abstract}
limited by various adverse effects. nutraceutical.

\section{Introduction:}

Caralluma fimbriata is a succulent plant, of the cactus family, that has been used as a natural appetite suppressant in India for centuries. It is the active ingredient of recent patents that are becoming increasingly popular for their appetite suppressant and weight loss properties, as well as their ability to improve glycemic control (1).
\end{abstract}

Abstract

Obesity is a major global health problem and a risk factor for several chronic disorders such as diabetes, hyperlipidemia, hypertension and cardiovascular disease.

There are various pharmacological treatments available for obesity but their use is

Caralluma fimbriata Wall. is a plant which has been used to suppress the hunger and caloric intake and also help increase the endurance people.

This review focus on patents related to caralluma fimbriata, as well as other

Key Words: Caralluma fimbriata Wall., Obesity, Nutraceutical drug, Suppress appetite

\section{History of Caralluma Species:}

Caralluma is belongs

Asclepiadaceae Family (Milkweed

family) and commonly known as

*Corresponding Author:

\section{Sharma Ravindra,}

P.G. Scholar, Dept. of P.G. Studies in Dravya Guna,

National Institute of Ayurveda,

Amer road Joravar Singh gate,

Jaipur, Rajasthan, India, 302002

Email: ravindramddg@gmail.com
'Yugmaphallottama' in Sanskrit, 'Maakada singi,' in Kannada, 'Makad Shing' in Marathi, Kullee Mooliyan in Tamil, and In English it is known as Caralluma fimbriata Wall.

Caralluma is an erect branched herb, 20-30 cm tall. Stems are leafless, 4angled, fleshy-green, tapering to a point. Leaves are minute, present only on young branches, soon falling off, leaving a toothlike projection on the angles. Flowers are borne at the end of branches, singly or 2-3 together on short stalks. Flowers are like wheels, $2 \mathrm{~cm}$ across.

Petals are narrow, purple with yellow marking, and margins frilly with hairs. Fruits are 10-12 cm long, cylindric with one of the pairs often suppressed. Caralluma is found in peninsular India. It has been eaten in rural India for centuries, raw, as a vegetable with spices, or preserved in chutneys and pickles, and is often found as a roadside shrub or boundary marker. It has been used as a 
portable food and thirst quencher for hunting. It is also used for its purported ability to suppress hunger and appetite and enhance stamina.

Tribesmen on a day's hunt will often only pack some Caralluma to sustain themselves and hence it is commonly considered a "famine food" in India. Key phytochemical ingredients include pregnane glycosides, flavone glycosides, megastigmane glycosides, bitter principles, saponins and various flavonoids $(2,3)$.

\section{Mechanism of action:}

Caralluma fimbriata is a nutraceutical derivative this is believed to inhibit the hunger sensory mechanism of the hypothalamus and increase satiety and satiation. It results in termination of adipogenesis and increased lipolysis, the end result being weight loss and reduced appetite for food (4).

The major ingredients present in the extract are pregnane glycosides, flavone glycosides, megastigmane glycosides, bitter principles, saponins and various other flavonoids which act at the hypothalamus and suppress appetite, promote lipolysis and reduce body fat mass. Caralluma fimbriata blocks the activity of citrate lyase and results in blockage of the formation of fat. This helps reduce body weight. In the adipose tissue, pregnane glycosides reduce lipogenesis $(5,6)$.

\section{Pharmacological option for obesity:}

The increasing epidemic of obesity has led to the need of effective management. Pharmacologic treatment and surgical treatment may be effective for decreasing the weight and reducing obesity, but in some circumstances are not always appropriate. Unfortunately, drug treatment of obesity despite short-term benefits, is often associated with rebound weight gain after the cessation of drug use, side effects from the medication, and the potential for drug abuse.
Pharmacologic options include sibutramine, orlistat, phentermine, diethylpropion, and fluoxetine or bupropion. Phentermine and diethylpropion have potential for abuse and are only approved for shortterm use. Approved medications for long term use in the treatment of obesity are sibutramine and orlistat. However, these agents should be used with caution in patients with a history of cardiovascular disorders, and may cause liver disease, respectively.

Caralluma fimbriata is a nutraceutical product which has no major adverse effects. Consequently its extract has beneficial advantage as compared to the western pharmacological and surgical treatment of obesity (7).

\section{Counseling of patients:}

Patients respond better to chronic drug therapy if they are counseled about its method of working.

Kreb's Cycle or the Citric Acid Cycle, takes place in the mitochondria, which are found in the cells of most living beings. Mitochondria are known as the body's "powerhouse" because they generate energy for the body from the food we eat. The body obtains energy when carbohydrates, especially glucose molecules are broken down through a process called catabolism. This process is coupled with the synthesis of a highenergy molecule called ATP (adenosine tri-phosphate) which provides chemical energy to the body, much like a car battery which converts chemicals to electricity.

Glucose is broken down into a compound called pyruvic acid, which enters the mitochondria. Pyruvic acid in turn is broken down to Acetic acid and ultimately, it is converted to Acetyl coenzyme $A$ and citric acid, hence the name Citric Acid Cycle. During this cycle, ATP is formed. The Kreb's Cycle described above, generates energy from glucose. What happens when too much energy is generated? This is stored by the body in 
the form of fat. When glucose rises, fat is formed in adipose (fat) tissue and in the liver through a process called gluconeogenesis. Fat is formed after the Kreb's Cycle and is synthesized in the form of fatty acids. The basic building block of fatty acids is Acetyl co-enzyme A, which is mentioned above. Now, for the formation of Acetyl Co-enzym A, a vital enzyme called citrate lyase is required. If this enzyme is blocked, then fat cannot be made by the body. Caralluma fimbriata contains pregnane giycosides which are believed to block the activity of citrate lyase. By blocking this enzyme, Caralluma fimbriata blocks the formation of fat by the body.

Further, Carallurna fimbriata also blocks another enxyme called Malonyl Coenzyme A. By blocking this enzyme, fat formation is further blocked and the body is forced to burn its fat reserves. This accelerates the rate of fat loss by the body (8).

\section{Adverse reaction of modern weight loss drug:}

There are various drugs available in present market for reducing weight. These conventional sympathomimetic drugs can work as appetite suppressants but they carry with them the risks associated with sympathetic stimulation. These adverse effects are similar to the thermogenic class of drugs and include cardiac disturbances, elevated blood pressure, anxiety, insomnia and hypersensitivity. Fen-Phen is an infamous example of cardiac side effects due to their mechanism of action.

Traditional health care systems, including nutraceutical medicine are widespread in developing countries. Various herbs, used by native people have been studied for their appetite suppressing effect, including Caralluma fimbriata Wall. It is also well known as a famine food, appetite suppressant and thirst quencher among tribal populations.
Ayurvedic (traditional Indian medicine) experts have noted that there are no adverse effects when using Caralluma fimbriata from long time and the plant has no known toxic ingredient $(9,10)$.

\section{Results of various researches on Caralluma fimbriata:}

The main reason why most weight-loss programs fail is that the patient always feels dull and tired after attaining weight loss. This makes the patient go back to his old eating habits and results in a rebound weight gain. Patients on Caralluma however, report feeling more energetic and have gained lean muscle mass, while losing fat. The reason 'for this is, that CaraIluma not only inhibits fat synthesis as mentioned above, it also increases the burning of fat. This makes more energy available to the body and makes the patient more active and lively.

According to the journal Appetite, researchers from Bangalore, India studied the effects of Caralluma fimbriata extract on 50 overweight men and women in a 2006 double-blind, placebo-controlled study. The study participants were divided into two groups; one group received a placebo and the other received one gram of Caralluma fimbriata extract a day for 60 days. At the end of the 60 days the placebo group experienced some weight loss but did not experience any statistically significant changes in any of the key measures that were taken, including body weight, BMI, hip and waist circumference, fat loss, or hunger levels (11).

In 2004, researchers from the Western Geriatric Research Institute in Los Angeles implemented a double-blind, placebo-controlled study, this time with 26 people. The study showed that more than 60 percent of the participants who took Caralluma fimbriata extract every day for one month lost six pounds or more, while the placebo group showed little to no weight loss. 72 percent of the participants taking the extract also had a reduction in 
waist circumference. The study concluded that Caralluma fimbriata does indeed promote weight loss and fat reduction. Participants taking the extract also reported greater energy levels (12).

Thus, by acting on different levels in the body's biochemical processes and brain function, Caralluma fimbriata works as an effective appetite suppressant and potent weight-loss agent; which are supported by various researches done by researcher through out of the world.

\section{Conclusion:}

Obesity is recognized as one of the major global health issues that requires intervention. Weight reduction by non pharmacological methods such as diet and exercise is advised, but these methods have limited effect in obese people. Drugs for obesity currently available in market have side effects which prevent their use in a large proportion of patient.

Caralluma fimbriata is a potential appetite suppressor that can be used as an effective and safe therapy for the management of obesity.

\section{References:}

1. Zakaria MNM, Islam MW, Radhakrishnan RR, Chen HB, Ismail A, Chan K, Habibullah M, Evaluation of antinociceptive and antiinflammatory properties of Caralluma arabica. J Pharm Pharmacol, 1999; vol. 51 (1); P. 117

2. Bader A, Braca A, De Tommasi N, Morelli I, Further constituents from Caralluma negevensis, J Phytochemistry, 2003; vol. 62 (3); P. 1277-1281

3. Hayashi K, Iida I, Nakao Yu, Nakao Yo, Kaneko K, Four pregnane glycosides, boucerosides, AI, AII, BI, and BII from boucerosia aucheriana, $\mathrm{J}$ Phytochemistry 1998; vol. 27 (2); P.3919-3924

4. Preuss HG, Bagchi D, Bagchi, M, Rao CVS, Dey DK, Das S, Satyanarayana
S, Weight management and mechanisms of action of a novel, natural extract of hydroxycitric acid (HCA-SX) and a combination of HCASX plus niacin-bound chromium and Gymnema sylvestre extract, Diabetes, Obesity \& Metabolism, 2004; vol. 6 (1); P. 171- 180

5. Ohia SE, Olubusayo A, LeDay AM, Opere CA, Bagchi D, Effect of hydroxycitric acid on serotonin release from isolated rat brain cortex, Res Comm Molec Pathol Pharmacol, 2001; 109 (6); P. 210-216

6. Radhakrishnan $\mathrm{R}$, Zakaria M, Islam MW, Liu XM, Chan K, Habibullah M, Antihyperglycemic effects of Caralluma arabica in diabetic mice, $\mathrm{J}$ Pharm Pharmacol, 1999; 51 (Suppl ); P. 116

7. Zhaoping Li, MD, Maglione Margaret, Tu Wenli, Mojica Walter, Arterburn David, Shugarman Lisa R, Pharmacologic Treatment of Obesity, Ann Intern Med, 2005; 142 (5); P. 532546

8. Ronald $M$ Lawrence and Suneeta Choudhary, Caralluma Fimbriata in the Treatment of Obesity, 12th Annual World Congress of Anti-Aging Medicine, Las Vegas, USA, December 2004.

9. O. Kunert, V. G. Rao, and V. G. Rao, Pregnane glycosides from Caralluma adscendens var. fimbriata, Chemistry and Biodiversity,2001; vol. 5 (2); P. 239-250

10. M. N. M. Zakaria, M. W. Islam, and M. W. Islam, Anti-nociceptive and anti-inflammatory properties of Caralluma arabica, Journal of Ethnopharmacology, 2001; vol. 76 (2); P. $155-158$

11. Kuriyan Rebecca, Raj Tony, Srinivas S.K., Vaz Mario, Rajendran R. and Kurpad A. V, Effect of Caralluma Fimbriata extract on appetite, food intake and anthropometry in adult Indian men and women, Division of 
Nutrition, Institute of Population Health and Clinical Research, St John's National Academy of Health Sciences, Bangalore 560034, India. Gencor Pacific Group, USA. Green Chem Limited, Domlur, Bangalore, India. Appetite, 2007; 48 (1); P. 338-344
12. Ronald M Lawrence and Suneeta Choudhary, Caralluma Fimbriata in the Treatment of Obesity, 12th Annual World Congress of Anti-Aging Medicine, Las Vegas, USA, December 2004. 